\title{
A short history of health technology assessment in Germany
}

\author{
Matthias Perleth \\ Gemeinsamer Bundesausschuss \\ Bernhard Gibis \\ Kassenärztliche Bundesvereinigung \\ Britta Göhlen \\ Deutsches Institut für Dokumentation und Information
}

Objectives: To provide an overview of the development of health technology assessment (HTA) in Germany since the 1990s.

Methods: Analysis of key documents (e.g. literature, laws, and other official documentation) and personal experiences.

Results: Health technology assessment (HTA) entered the political agenda in Germany only in the mid-1990s, basically as the result of a top-down approach toward more efficiency in health care, but with a strong impetus of an evidence-based medicine movement. Accordingly, HTA became part of several healthcare reform laws since 1997, which led to the establishment of the Federal Joint Committee (G-BA) and the Institute for Quality and Efficiency in Health Care (IQWiG) in 2004. This tandem construction aims at using evidence in decision-making processes for coverage and other decisions.

Conclusions: These developments have led to a considerable impact of HTA in Germany. In addition, a broad spectrum of activities at universities and in other organizations, such as the German Institute for Medical Documentation and Information (DIMDI), can be observed that contribute to both teaching and research in HTA. German researchers in the field of HTA are actively involved in international projects, such as EUNetHTA, and contribute to scientific conferences and journals.

Keywords: Health technology assessment, Germany, Federal joint committee, G-BA; Social health insurance, SHI

\section{GERMAN HEALTHCARE SYSTEM}

The Federal Republic of Germany is situated in central Europe, between Baltic and North Sea in the north and the Alps in the south. It covers an area of approximately $357,000 \mathrm{~km}^{2}$. The country shares borders with Denmark, Poland, the Czech Republic, Austria, Switzerland, France, Luxembourg, Belgium, and the Netherlands. Germany has 82.5 million inhabitants.

\section{Central Versus Decentralized Control}

Germany is a federal republic consisting of sixteen states, which have principal legislative authority for many areas. Health care is mainly decentralized. Three main groups are involved in the organization of the system. These are the federal government, the federal state governments, and the corporate bodies that comprise the sickness funds, the physicians associations, the hospital organizations, and, with increasing responsibility and rights, patient representatives.

The Federal Ministry of Health sets the legal framework of the healthcare system including the principal benefits to be covered by the statutory health insurance system (SHI). The Ministry supervises six federal agencies, including agencies for licensing and supervision of pharmaceuticals, sera, vaccines, and medical devices. The legal framework is laid out in the Social Code Book V (SGB V).

The federal states are responsible to maintain the hospital infrastructure but also in the field of public health (mainly 
supervision and monitoring activities of personnel, goods and diseases), undergraduate medical, dental, and pharmaceutical education, and supervision of regional physician and sickness fund organizations.

Corporate bodies comprise the associations of sickness funds, physicians, and dentists. The latter two corporate institutions have the full obligation to secure the actual provision of all direct and acute healthcare services in ambulatory care. The monopoly suggests that hospitals, communities, sickness funds, and others do not have the right to offer ambulatory medical care with some exceptions, however. The most important corporate body is the Federal Joint Committee (Gemeinsamer Bundesausschuss, G-BA), formed by the national associations of doctors and dentists, the German Hospital Federation and the National Association of Statutory Health Insurance Funds. The G-BA has wide-ranging regulatory powers that encompass coverage of innovative diagnostic and therapeutic services, quality assurance of ambulatory and hospital treatment, regulation of drugs (except market licensing), dental treatment, prevention and screening, psychotherapy, rehabilitation, and palliative care (9).

\section{Insurance and Payment}

The German healthcare system is a so called Bismarck system, a statutory health insurance system (SHI). Approximately 14 percent of the population is privately insured or covered by specific governmental schemes (e.g., military, police). In mid-2008s, there were 218 public insurance funds that insured a total of just over 70 million people, a share of 85.5 percent of the German population (for more statistical details see www.bmg.bund.de and www.destatis.de).

In 2006, the total healthcare budget was $€ 245$ billion ( $\sim$ US $\$ 350$ billion) or 10.6 percent of the gross domestic product, equal to $€ 2,970$ per capita ( $\sim$ US $\$ 4,300$ per capita). In total, three quarters ( $€ 140$ billion) of spending in health care is financed through public sources (including premiums by SHI insurees, tax subsidies, and other insurance contributions). Private households contribute 14 percent, employers 4 percent, and private insurance 9 percent of the total share (www.destatis.de). Important trends over the last years are an increase in out-of-pocket payments and a move toward more privatization and diversification in contracting aiming at the introduction of market mechanisms. Risk selection is of relevance at all levels of the healthcare system. A major change in the risk compensation scheme between sickness funds in combination with a controversial centralized premium collection system (so-called health fund), which will come into effect in 2009 and will result in increased SHI premiums.

\section{BENEFITS CATALOG AND ACCESS TO CARE}

The benefit catalogue is rather comprehensive, including prevention and screening, immunization, diagnostic procedures, treatment of disease, and transportation. Treatment includes all necessary and state-of-the-art ambulatory medical care, dental care, drugs, nonphysician care, medical devices, hospital care, home nursing care, palliative care, and rehabilitation. Few services are explicitly excluded (e.g. drugs for common cold, life-style drugs). Germany has no gate-keeping system, and patients are free to choose among 140,000 physicians and psychotherapists, which also includes basically unrestricted access to specialist care. Not a part of the common benefits catalogue are "IGeL" services to be paid outof-pocket but provided by physicians within the SHI. The majority of IGeL services lack a sound evidence base.

\section{Pharmaceuticals}

After they have a marketing license, drugs are covered by German health insurance as long as they are not excluded from reimbursement. The pharmaceutical market is probably the most regulated in German health care, but cost increases are nonetheless above the average increase of costs of other services in health care. As a matter of principle, drugs are not covered by SHI when they are not prescription drugs (with some exceptions). Lifestyle drugs are excluded too. In addition, there are several regulations regarding pricing (e.g., reference based pricing), second opinion, off-label use and others. Still some special privileges apply with respect to the pharmaceutical industry. As the OECD states: "Germany is also unusual in that the reimbursement level on on-patent pharmaceutical products for which there are no therapeutic comparators is defined according to the list price proposed by the manufacturer without negotiation. Coverage is automatic and does not depend on any assessment of value or budget impact" (19). However, on a single case basis pharmaceuticals without proven benefit can be excluded from the benefit package, which has been done in the past (e.g., clopidogrel for secondary prevention of myocardial infarction or stroke, see Bundesministerium für Gesundheit) (7). Currently, economic evaluation as part of the IQWIG-evaluation process of pharmaceuticals is in preparation.

\section{Medical Treatment}

The differing and inconsistent regulations for coverage and steering of services between hospitals and ambulatory medical care are a result of the clear-cut separation of inpatient and outpatient care in Germany. It is, therefore, necessary to look at these two sectors separately. In both sectors for the purpose of a standardized documentation of diseases and procedures the International Statistical Classification of Diseases and Related Health Problems (ICD) and the German Procedure Classification (OPS) are implemented.

Hospital Treatment. In the hospital sector, innovations need to be fitted into a diagnosis-related group (DRG). After approval of calculations individual hospitals have to provide to the Institute for the Hospital Remuneration System, an existing DRG may be changed to cover additional costs of an innovation. Alternatively, a new DRG can be 
created. As a matter of fact, each year up to one hundred new DRGs enter the hospital remuneration system. An assessment of effectiveness or efficiency is not part of this procedure (9). Therefore, hospital-based health technologies are reimbursed by SHI as long as they are not explicitly excluded by the G-BA because of lack of benefit ("Verbotsvorbehalt"). Only in exceptional cases the G-BA is involved in such hospital-based coverage decisions, that is, when exclusion of a service is explicitly asked for. However, such decisions usually involve rare indications of some multipurpose technologies (e.g., hyperthermia, proton beam therapy) where controversies exist concerning their effectiveness and safety. Consequently, until 2004 only few decisions were taken (9).

Ambulatory Treatment. For the ambulatory sector a comprehensive benefit catalogue (so called Uniform Value Scale) with approx. 4,500 diagnostic and therapeutic interventions is in place (see below). Each new service in the ambulatory sector deserves an explicit, health technology assessment (HTA)-based positive coverage decision. Thus, health technologies are not reimbursed by SHI as long as the G-BA has not approved the new service ("Erlaubnisvorbehalt"). Only drugs are immediately covered after they are licensed (exemptions apply, see above). For the evaluation of the dynamic field of lab testing, a rapid HTA process is currently under construction to allow quick market access for those technologies that are worth covering. Overall, the ambulatory sector is more regulated than the hospital sector.

The national and state-level physician associations have the obligation to secure the actual provision of all direct and acute healthcare services in the ambulatory sector. Ambulatory care physicians operate on a private basis and are reimbursed according to the Uniform Value Scale, which forms the basis for Germany's fee-for-service system. The scale contains a description of complex and single services as well as of laboratory services. It is negotiated between physicians and sickness funds in a separate federal standing committee. Without being listed in the Uniform Value Scale, a service cannot be reimbursed, even if the G-BA already approved a new technology. On the other hand, without approval of the G-BA, a new service cannot be reimbursed.

\section{Preventive Services}

Several cancer screening and other primary and secondary prevention programs are in place (e.g., regular health checks for children, adolescents, and pregnant women), which are managed by the G-BA (21). Since 2007, immunizations are also included in the benefit package of the statutory health insurance; the G-BA is in charge of approving recommendations by the Federal Immunization Committee (Stiko) within 3 months. HTA plays a central role in shaping these preventive measures. Other preventive services are the responsibility of the federal states and communities (e.g., hygiene of health and social institutions, surveillance of infectious diseases, monitoring of health indicators).

\section{PUBLIC POLICIES INTENDED TO CONTROL PRACTICE AND HOSPITAL CARE}

In addition to the aforementioned inconsistent regulation of health technologies in the hospital and ambulatory care sector, a mixture of regulations and policies exist for managing service utilization, quality assurance, diffusion of technologies, and preventive services. These measures are mostly restricted to the hospital or the ambulatory sector (with some recent exceptions). It is not possible to give a comprehensive overview within the framework of this study, but only some general remarks.

\section{Utilization of Services}

Management of service provision on the supply-side is relatively weak in Germany, and it is hardly possible to measure any effects. Among the more global measures are budgets and standards for qualifications as prerequisites for delivering technical services (technical standards for devices and for physicians performing procedures, such as ultrasound imaging or endoscopy, usually have a quantitative effect). On the demand side, moderate levels of co-payments and deductibles are in effect, but exemption rules exist to avoid financial strains on chronically ill patients.

\section{Diffusion of Technologies}

There are no effective regulations concerning diffusion of medical technologies in Germany. On the level of the federal states, it is possible within the context of hospital planning to steer the diffusion of technologies by defining locations and modifying hospital profiles in terms of functional units and bed numbers. Within the framework of quality assurance standards, it is possible to restrict the number of physicians providing technical services in ambulatory care. For several technologies, the G-BA chose the "introduction under evaluation" approach. This applies for example for mammography screening or acupuncture for certain indications. The experience has been rather positive so far. In addition, for a quite a number of technologies, a negative decision induced primary research in form of randomized controlled trials. Just in 2008, a technology that has been previously declined for the reason of insufficient proof of evidence got accredited due to presentation of favorable, high-quality randomized controlled trials. However, a needs-based approach to diffusion of health technologies has not yet been established in Germany.

\section{Quality Assurance}

Agreements about structural, procedural, and outcomeoriented quality measures play an increasing role in German health care. The central decision-making body is the G-BA, which has been charged by the several healthcare reform laws (see below) with competencies to regulate quality assurance in a broad range of areas of service provision. These 
competencies comprise among others quality reporting of hospitals, rules for quality management of ambulatory practices, definition of quality standards of technical services, qualification requirements of physicians providing certain services, trans-sectoral quality assurance agreements of diagnostic and therapeutic technologies, and minimum-frequency regulations for specialized treatments.

\section{HTA IN GERMANY: FIRST STEPS}

Legislation in German health care has been relatively consistent during the past 20 years regarding the introduction of quality assurance, evidence-based medicine, and HTA. This development took place independently of the political party affiliation of the respective ministers of health. Some milestones, however, need to be mentioned:

Until 1997, the only decision-making body responsible for coverage decisions existed in the ambulatory care sector, the Federal Standing Committee of Physicians and Sickness Funds, dating back to $1923(11 ; 13)$.

The 2nd Health Insurance Restructuring Act gave the Federal Standing Committee new competencies in July 1997. It became now responsible for a technology assessment of new technologies as well as of the existing catalogue of ambulatory benefits, for defining a positive list for care by nonphysicians and for guidelines defining rehabilitative entitlements (4). This role was strengthened with the 2000 healthcare reform law (Statutory Health Insurance Reform Act of 2000), which established a Coordinating Committee (the direct predecessor of the G-BA) that had the additional mandate of technology assessment in the hospital sector (5).

Based on the same law, the Federal Ministry of Health ordered the German Institute for Medical Documentation and Information (DIMDI) to implement and operate an information system on HTA and evidence-based medicine. The information system provides scientific research material as a basis for decisions in health policy, especially for the purposes of the SHI.

In 2004, another healthcare reform act (Statutory Health Insurance Modernization Act) established the G-BA, which has become since then an important decision-making body with far reaching competencies (6).

All together, these health reform laws established a considerable impact of HTA in the German healthcare system because coverage decisions require a transparent and evidencebased assessment of the effects of health technologies.

\section{EVALUATION AND ASSESSMENT}

\section{Introduction of HTA in Germany}

It is not possible to separate the evidence-based medicine movement (e.g., the German Cochrane Initiative) from other concurrent developments in Germany, such as HTA, health economics, and guidelines development and implementation.
There was (and still is) a substantial overlap between the opinion leaders of these movements in Germany. A good example is the foundation of the German Network of Evidencebased Medicine (DNEbM) in 1998 as an umbrella organization with the aim of better cooperation (23). The DNEbM established from the beginning several working groups that reflected all these movements and in addition clinical guidelines development, quality assurance, and health economics (see www.ebm-netzwerk.de).

However, the uptake of several concurrent movements taking place in Germany was only one aspect in the introduction of HTA into the German healthcare system. A clearly crucial aspect was the strong interest by the Ministry of Health, which led as the most important outcome to legal changes that made the use of HTA mandatory for many coverage decisions. Another aspect was the growing awareness of tight budgets in the healthcare sector and the overall agreement between stakeholders of a need for measures to contain costs while improving the quality and efficiency of health care. Evidence-based health care was seen as the key to this aim and as such advocated by the Advisory Council of the Germany Ministry of Health (27).

In the mid-1980s and early 1990s, some small working groups were concerned with so-called big ticket technologies, especially extracorporal shock-wave lithotripters and computed tomographs from the perspective of needs-based planning and technology diffusion (14-17). However, these approaches were largely university-based research activities and their impact was limited.

A feasibility study funded by the Ministry of Health between 1995 and 1997 stimulated early HTA activities in Germany from the viewpoint of coverage decision making $(2 ; 20)$. This initiative developed into the German HTA Project and gained importance with respect to the further unfolding of HTA activities in Germany. The German HTA Project was also charged with the formation of a strategy for the implementation of HTA in Germany (1).

One of the ideas behind this project was that database content (e.g., from the Cochrane Library) could be transferred or translated into the German context and thus used for decision-making purposes. However, it turned out that this was not achievable without problems and thus the idea was not maintained. Instead, it became obvious that Germany had to produce its own HTA reports to properly inform decision making in health care. During this and follow-up projects, methodological standards of the HTA process were developed or adapted to the German healthcare system and tested in some pilot HTA projects (3). As part of this initiative, the German Scientific Working Group on Technology Assessment for Health Care at the Hannover Medical School was founded and produced a set of approximately fifty HTA reports between 1997 and 2002. These reports built the foundation of the German HTA database, maintained at the DIMDI (see below). The Working Group drew on international standards but increasingly contributed to international projects 
(e.g., HTA Europe, ECAHI/ECHTA; see also Busse et al.) (8).

It became clear very early during this phase that major efforts were needed for academic capacity building to provide enough qualified personnel for writing HTA reports. This led to the concept of "academic vanguards": based at several universities, academic working groups should receive continuous funding to enable methodologically sound production of HTA reports and proper qualification of skilled people to ultimately achieve a "critical mass" of "HTA doers" that would meet the needs in the healthcare system (2).

\section{Growing Influence of HTA in Germany}

The SHI Reform Act of 2000 charged the German Institute for Medical Documentation and Information (DIMDI) with the continuous administration of a federally funded HTA program and establishing a database of relevant HTA results with the aim of supporting decision-making processes in health care. Within DIMDI, the German Agency of Health Technology Assessment (DAHTA) was established and still manages the German HTA program with a comparatively small but constant annual budget (12). DAHTA commissions approximately seven HTA reports per year to academic and nonacademic working groups in Germany and Austria. These reports are the foundation of the DIMDI HTA database, which is freely available on the Internet (www.dimdi.de/dynamic/de/hta/db/index.htm and www.egms.de). Suggestions for research topics are submitted by the public by means of an internet questionnaire. Topic selection is the task of a board of trustees, which represents the relevant stakeholders in German health care. In addition, a scientific advisory body advises DAHTA on the further development of the program (12).

Whereas the initiative of the Ministry of Health was fundamental to the rapid development of HTA in Germany, it was not the only initiative. Within several medical societies, HTA working groups were established (e.g. in the German Society for Social Medicine and Prevention) and in 2000, the German HTA Society was founded. The latter society (www.health-technology-assessment.de) took responsibility of hosting the 18th (and final) Annual Meeting of the International Society of Technology Assessment in Health Care (ISTAHC) in 2002 in Berlin. This most important international HTA conference to be held in Berlin can be seen as the end point of the phase of establishing HTA in Germany. The meeting created a lot of publicity in German media and was supported by the Ministry of Health and many other relevant national organizations.

Under the auspices of the Germany HTA Society, a curriculum for teaching HTA in Germany was developed (24) and this curriculum will be the basis of an online course for HTA at the Technical University of Berlin.

Important to the diffusion of HTA into the German healthcare system was, beside the above mentioned health reform acts, the commitment of the medical service of sickness funds and its federal organization (MDS). The medical service is financed by the statutory sickness funds and organized into regional services at the level of the federal states where it is concerned with coverage decisions of individual patients seeking payment of experimental or very expensive treatments. All together, around 2,000 highly qualified physicians are working within this service. They are also organized in nation-wide expert working groups coordinated by the MDS. These working groups provide HTA reports concerning innovative technologies commissioned by sickness funds. Experts of this system are also involved in consultations regarding evaluation of innovations in the G-BA. In this way, a bottom-up understanding (including early warning) meets decision making on a federal level (18).

Another institution that merits attention in the context of technology assessment in Germany is the Office of Technology Assessment at the German Parliament (TAB). The prevailing themes of evaluation focus on biotechnology, such as genetically based technologies (gene therapy, genetic testing), but also on nanotechnology, brain imaging, and telemedicine. Much of these evaluations attempt to contribute to discussions about the value of these technologies in a societal perspective and feed into the law making debates. The TAB is commissioned by the Committee on Education, Research, and Technology Assessment of the German Parliament for advice about the direction in which research and education policy should be moving. Evaluation methods differ in comparison to the traditional approach of HTA with an emphasis on safety and efficacy. Thus, due to the entirely different focus of the work of the TAB in comparison to that of the G-BA or the Institute for Quality and Efficiency in Health Care (IQWiG; see below), the links between them are limited (22).

In 2004, the former Federal Standing Committee of Physicians and Sickness Funds together with the Hospital Committee (both were under the umbrella of the Coordinating Committee since 2000) were transformed into the G-BA. The G-BA is the supreme decision-making body of the self-governed healthcare system in Germany. Physicians, dentists, hospitals, sickness funds, and patients are represented in the G-BA. The G-BA issues directives and thus determines the benefit package of the statutory health insurance.

The establishment of the IQWiG in the same year can be seen as a further step toward the use of HTA and evidencebased medicine in Germany. The IQWiG commissions evidence reports on behalf of the G-BA and feeds them into the decision-making process of the G-BA, but has no decisionmaking powers itself. G-BA and IQWiG can be seen as a tandem where G-BA commissions the IQWiG with technology assessments that are appraised by the G-BA according to the principles of effectiveness, necessity, and cost-effectiveness. Due to its rigorous approach to the assessment of clinical evidence the IQWiG has confronted frequent attacks from 
different groups such as pharmaceutical industry, medical societies, and patient organizations.

It is notable that also physicians' organizations on the national level adopted HTA as a tool to clarify the virtues of technologies and to issue recommendations. This can be interpreted as an example for the diffusion of HTA as a health planning technology that reached acceptance among several stakeholders.

Several developments with regard to strengthening the role of HTA in Germany could be mentioned:

- Teaching: HTA has been introduced as a teaching subject in many postgraduate courses in public health, healthcare management, and health economics in Germany. Recently, a curriculum was published that recommends basic contents of teaching courses for users as well as for producers of HTA reports with regard to the peculiarities of the German healthcare system (24). In addition, the first comprehensive textbook on HTA in German language has been published recently (25).

- Concept-related discussions: During scientific meetings and within influential German scientific journals, concepts of HTA are discussed in depth. Some recent examples are ethical aspects in HTA (10) or a special theme issue on the organizational, legal, and sociocultural scope of HTA in the German Journal for Evidence and Quality in Health Care [Zeitschrift für Evidenz, Fortbildung, und Qualität im Gesundheitswesen] (see Vol. 102, 2008: http://www.sciencedirect.com/science/journal/18659217).

- Research: National research projects have been started aiming at early HTA in the developmental phase of medical devices and tissue engineered products (see www.metaforum-innovation.de/) and on the ethical, legal, and economical consequences of expensive biomedical innovations (28).

- Collaboration with European (e.g., European Network for HTA/EUnetHTA) or international HTA groups (e.g., HTA international / HTAi, International Network of Agencies for HTA/ INAHTA) helps to develop methods for HTA meeting international standards.

\section{DISCUSSION}

Although HTA did not play an important role in Germany until the mid-1990s, the impact of HTA on coverage decisions, especially in ambulatory care, is high. The reason for this lies in the fact that HTA was adopted by an already existing, powerful decision-making body, and this was supported by health policy. Sickness funds and physician organizations both favored this approach. Accordingly, healthcare reforms increasingly strengthened the role of the G-BA and its predecessor organizations. Another important factor supporting the rapid uptake of HTA in Germany was its codevelopment with the evidence-based healthcare movement advocated by influential researchers and opinion-leaders in the field of medicine in Germany.

However, HTA failed to assume such a decisive role in the hospital sector. Under this constellation, it is difficult to manage the introduction of innovations that may be provided in both hospital and ambulatory care settings. Although quality assurance measures can be mandated to regulate service provision trans-sectorally, they cannot substitute for the assessment of efficacy, safety, or cost-effectiveness. In addition, a technology may be covered during a hospital stay and at the same time not covered outside the hospital. As a consequence, coverage decisions, especially in the hospital sector, are difficult to reach and they are usually highly controversial.

Another topic for consideration is the weak position of economic evaluation within coverage decision making in German health care. Although evaluation of economic aspects are a mandatory part of HTA reports in the German HTA program at DIMDI and health economics is a well established discipline at German universities, it plays only a minor part in healthcare-related decisions. A recent analysis of coverage decisions of the G-BA between 1998 and 2007 revealed that aspects of efficacy and rarely safety were decisive, but efficiency was not (26). This fits in the picture that a culture of efficiency analysis is not (yet) established in Germany, although German health care is suffering from the problem of scarce resources as most other healthcare systems do.

Until now the decision-making process about new health technologies still takes a long time. Many factors and aspects have to be considered in addition to benefit assessment. Until now there is no international standardized methodology for HTA available, for example, ethical, social, and legal aspects are not discussed in all cases. Furthermore, there are private actors on the HTA market and, therefore, a risk for HTA influenced by industry is possible. Some standards of conducting and reporting HTA reports should be established, for example, declaration of possible conflicts of interest.

Lately an increase in clinical research and in the quality of clinical trials can be observed. In addition, there is a stronger focus on patients' needs: patients actively participate in topic selection; selected topics are directed to prevention and screening (gain of knowledge to avoid illness) and to other aspects of relevance to patients (e.g., adherence or quality of life). Nevertheless, political discussions on health care are focusing more on patients as individually responsible partners.

Although HTA has steadily gained importance in the public healthcare system, criticisms revolve around its technocratic and to some also bureaucratic nature. For some patient advocacy groups, HTA imposes as just another way to say "no" or to delay decisions. It will be of crucial importance for the future of HTA in Germany to actively involve patient groups and the media to gain acceptance for HTAbased decisions. If the process is perceived as just and fair unfavorable outcomes of a decision are more likely to get endorsed by all stakeholders.

Finally, after gathering experience with the application of HTA for almost 10 years in the real-world decision-making 
process of an SHI system, two neighboring fields deserve special attention: research and quality assurance. Often HTA identifies research gaps that sometimes painfully limit the ability to reach a decision (for example the lack of comparative studies of magnetic resonance imaging and positron emission tomography). These research gaps arise often due to a lack of interest both of the industry and academia. HTA should systematically raise the awareness for these missing pieces of evidence and feed the research agenda. One approach could be the gathering and publication of those topics on national and international level. Second, the application of technologies in health care often requires quality assurance measures. Frequent questions are: Who is qualified to provide the new intervention, which setting is required (hospital and/or ambulatory), which kind of documentation is needed, what kind of quality indicator might be useful to monitor the appropriate usage of a specific technology? All those questions can potentially be answered by an HTA report that provides the nucleus for subsequent quality assurance measures. Both fields-health research and quality assurance-are closely linked to HTA and should get woven into a comprehensive fabric, which enables decision makers to reach scientific sound and appropriate conclusions.

\section{CONTACT INFORMATION}

Matthias Perleth, MD, MPH (Matthias.perleth@g-ba.de), Head, Department of Methodological Advice, Federal Joint Committee, Auf dem Seidenberg 3a, Siegburg, 53721

Bernhard Gibis (bgibis@kbv.de), Position: Director, Department for Service Contracts, Kassenärztliche Bundesvereinigung, 2, Herbert Lewinplatz, 10623 Berlin, Germany

Britta Göhlen, PhD (britta.goehlen@dimdi.de), Leader, German Agency for HTA (DAHTA), German Institute for Medical Documentation and Information (DIMDI), Waisenhausgasse 36 38a, 50676 Cologne, Germany

\section{REFERENCES}

1. Bitzer EM, Dörning H, Röseler S, et al. Current initiatives in health technology assessment-lessons for Germany. Annu Meet Int Soc Technol Assess Health Care Int Soc Technol Assess Health Care Meet. 1997;13:100.

2. Bitzer E, Busse R, Dörning H, et al. Bestandsaufnahme, Bewertung und Vorbereitung der Implementation einer Datensammlung 'Evaluation medizinischer Verfahren und Technologien' in der Bundesrepublik. Baden-Baden: Nomos; 1998.

3. Bitzer EM, Busse R, Kohlmann T, Lühmann D, Perleth M. Health Technology Assessment im internationalen Kontext: Wo steht Deutschland? Z Arztl Fortbild Qualitatssich. 1999;93:3338.

4. Bundesminister für Gesundheit. Zweites Gesetz zur Neuordnung von Selbstverwaltung und Eigenverantwortung in der gesetzlichen Krankenversicherung (2. GKVNeuordnungsgesetz-2. GKV-NOG). BGBl. 1997;I:1520-1536.
5. Bundesminister für Gesundheit. Gesetz zur Reform der gesetzlichen Krankenversicherung ab dem Jahr 2000 (GKVGesundheitsreformgesetz 2000). BGB1. 1999;I:2626-2656.

6. Bundesminister für Gesundheit. Gesetz zur Modernisierung der gesetzlichen Krankenversicherung (GKVModernisierungsgesetz-GMG). BGB1. 2003;I:2190-2258.

7. Bundesministerium für Gesundheit. Bekanntmachung eines Beschlusses des Gemeinsamen Bundesausschusses über eine Änderung der Arzneimittel-Richtlinie in Anlage 10: Clopidogrel. BAnz. 2008 Nr. 80:1949.

8. Busse R, Orvain J, Velasco M, et al. Best practice in undertaking and reporting health technology assessments. Working group 4 report. Int J Technol Assess Health Care. 2002;18:361422.

9. Busse R, Riesberg A. Health care systems in transition: Germany. Copenhagen: WHO Regional Office for Europe on behalf of the European Observatory on Health Systems and Policies; 2004.

10. Droste S, Gerhardus A. Ethische Aspekte in Kurz-HTABerichten-eine systematische Übersicht. Z Arztl Fortbild Qualitatssich. 2003;97:711-715.

11. Gibis B, Rheinberger P. Erfahrungen mit und Impact von Health Technology Assessment im Bundesausschuss der Ärzte und Krankenkassen. Z ärztl Fortbild Qualitatssich. 2002;96:82-90.

12. Göhlen B, Rüther A. Health Technology Assessment beim DIMDI. Kongress Medizin und Gesellschaft 2007. Augsburg, 17-21 September 2007. Düsseldorf: German Medical Science GMS Publishing House; 2007, Doc 07gmds534.

13. Jung K, Gawlik C, Gibis B, et al. Bundesausschuss der Ärzte und Krankenkassen: Ansprüche der Versicherten präzisieren. Dtsch Arztebl. 2000;97:A365-A370.

14. Kirchberger S. Unkalkulierte Folgen mangelhafter Planung im Gesundheitswesen-das Beispiel Nierenlithotripsie. Arb Sozialpolit. 1988;42:320-329.

15. Kirchberger S. Überlegungen zu Diffusion und Kosten medizinischer Technik. In: Schwartz FW, Badura B, Brecht JG, Hofmann W, Jöckel KH, Trojan A, eds. Public Health. Texte zu Stand und Perspektiven der Forschung. Berlin: Springer; 1991:421-443.

16. Kirchberger S. Health care technology in Germany. In U.S. Congress Office of Technology Assessment, ed. Health care technology and its assessment in eight countries. Washington DC: US Government Printing Office; 1995:137-170.

17. König HH. Steuerung der Anschaffung und Nutzung medizinisch-technischer Großgeräte. Internationaler Vergleich, Möglichkeiten und Probleme. Tübingen: Eberhard-KarlsUniversität Tübingen; 1993.

18. Mayer ED, Boukamp K, Kruse F, Hansis ML, Windeler J. Die evidenz-basierte wissenschaftliche Analyse als Grundlage MDK-interner Grundsatzgutachten. Z Arztl Fortbild Qualitatssich. 2001;95:113-119.

19. OECD Health Policy Studies. Pharmaceutical Pricing Policies in a Global Market. Paris: OECD Publications; 2008.

20. Perleth M, Busse R. Health technology assessment in Germany: Status, Challenges, and Development. Int J Technol Assess Health Care. 2000;16:412-428.

21. Perleth M, Busse R, Gibis B, Brand A. Evaluation of preventive technologies in Germany-Case studies on mammography, prostate cancer screening and fetal ultrasound. Int J Technol Assess Health Care. 2001;17:329-337. 
22. Perleth M, Wild C. Possibilities for partial integration of Health Technology Assessment (HTA) and Technology Assessment (TA). TA-Datenbank-Nachrichten. Zurich: ITAS; 2001:5558.

23. Perleth M, Lühmann D, Antes G. Das Deutsche Netzwerk Evidenzbasierte Medizin-DNEbM. Bundesgesundheitsblatt Gesundheitsforschung Gesundheitsschutz. 2006;49:278282.

24. Perleth M, Gerhardus A, Lühmann D, Rüther A. Das Curriculum Health Technology Assessment (HTA). Z Arztl Fortbild Qualitatssich. 2006;100:297-302.

25. Perleth M, Busse R, Gerhardus A, Gibis B, Lühmann D, eds. Health Technology Assessment: Konzepte, Methoden, Praxis für Wissenschaft und Entscheidungsfindung. Berlin:
MWV Medizinisch Wissenschaftliche Verlagsgesellschaft; 2008.

26. Perleth M, Gibis B. How are coverage decisions in German health care justified? Analysis of decisions between 1998 and 2007. In: Proceedings of the 5th Annual Meeting of HTAi, Montreal, Canada. August 8, 2008.

27. Sachverständigenrat für die Konzertierte Aktion im Gesundheitswesen. Gesundheitswesen in Deutschland. Kostenfaktor und Zukunftsbranche. Band II: Fortschritt und Wachstumsmärkte, Finanzierung und Vergütung. Baden-Baden: Nomos; 1998.

28. Strech D, Börchers K, Freyer D, et al. Ärztliches Handeln bei Mittelknappheit. Ergebnisse einer qualitativen Interviewstudie. Ethik Med. 2008;20:94-109. 